\title{
An Expert System for Inventory Replenishment Optimization
}

\author{
Ander Errasti ${ }^{1}$, Claudia Chackelson ${ }^{1}$, and Raul Poler ${ }^{2}$ \\ ${ }^{1}$ Industrial Organisation, Tecnun-School of engineering, University of Navarra, Spain \\ ${ }^{2}$ CIGIP, Universidad Politécnica de Valencia, Spain
}

\begin{abstract}
Companies survive in saturated markets trying to be more productive and more efficient. In this context, to manage more accurately the finished goods inventories becomes critical for make to stock production systems companies. In this paper an inventory replenishment expert system with the objectives of improving quality service and reducing holding costs is proposed. The Inventory Replenishment Expert System (IRES) is based on a periodic review inventory control and time series forecasting techniques. IRES propose the most effective replenishment strategy for each supply classed derived of an ABC-XYZ Analysis.
\end{abstract}

\section{Introduction}

Some authors argue that Operational Research could contribute by developing models that link the effectiveness of new forecasting methods to the organizational context in which the models will be applied [1].

Even if future demand information is scarce, Make to Stock Production systems needs more accurate demand forecasting in order to improve quality service and reduce holding costs.

This paper explores the development of a expert system based on a periodic review inventory control, which forecast future demands more accurately beneath the time series techniques with less forecast error and proposing the most effective replenishment strategy for each supply classed derived of an $\mathrm{ABC} / \mathrm{XYZ}$ analysis.

This research has also conducted a case study from Original Equipment Manufacturers (OEM) point of view answering the difficulties mentioned above.

The research methodology behind the work presented in this paper, consists of a theory-building phase, a theory-testing phase and a synthesis phase:

- Theory-building: started with an extensive literature review to identify the issues/factors to be considered in the implementation of an inventory management optimization based on time series forecasting.

- Theory-testing: designed around action research principles. Action Research can be seen as a variation of case research [2], in which the action researcher is not an independent observer [3].

- Conclusions/Synthesis: in the synthesis phase the conclusions of the case study and the findings are shown, which increase the understanding of the reengineering process and the techniques based on time series forecasting techniques. 


\section{Literature Review}

\subsection{Supply Chain Management}

Companies have to survive in saturated markets through competitiveness, trying to be more productive, more efficient or more innovative [4]. The APICS Dictionary [5] describes the supply chain as the processes from the initial raw materials to the ultimate consumption of the finished product, via different agents (suppliers, manufacturing plants, warehouses, customers, etc,). Supply Chain Management coordinates and integrates all activities of planning, sourcing, manufacturing and delivery. Some authors [6] classify and define the production strategies as make-to-order (MTO), maketo-stock (MTS) and assemble-to-order (ATO). They relate these approaches to choosing the master production scheduling (MPS) approach. Other authors [7] add the engineer-to-order production strategy and state that the decoupling point is a key issue [8]. The decoupling point concept is also known as order penetration point [9]. The customer order decoupling point decouples operations in two parts. Upstream this point the activities are performed to forecast and downstream they are performed to customer order (see Figure 1). The product differentiation point is the point where the firm's product is configured and it takes on specific features.

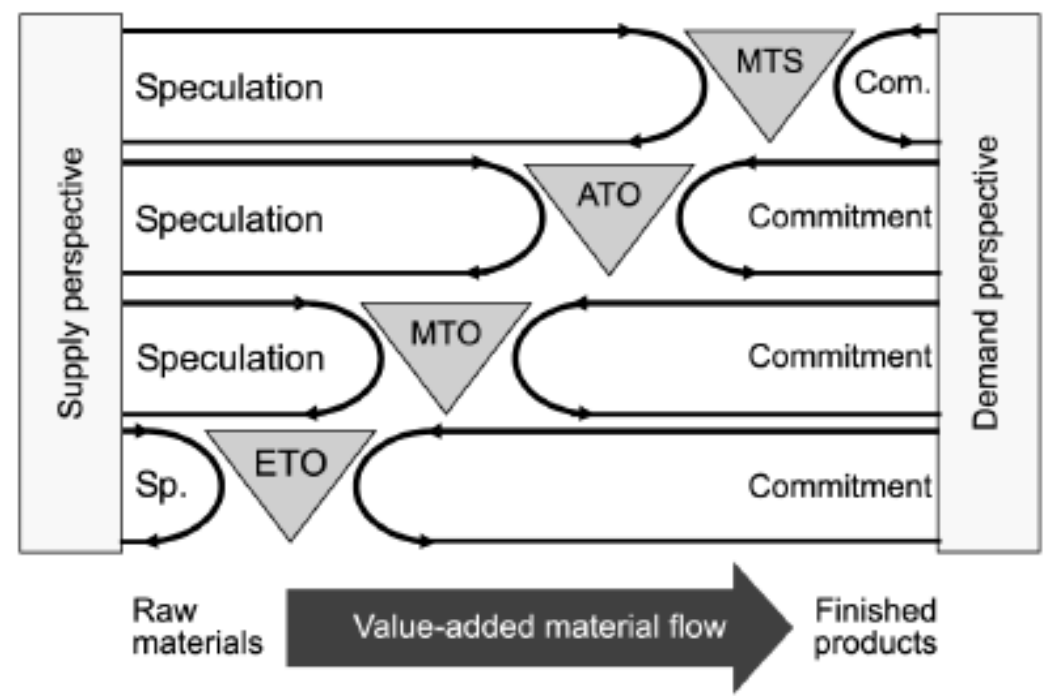

Fig. 1. MTS, ATO and ETO production strategy

In make-to-stock (MTS), the MPS is based on end items, and these end products are produced to meet forecast demand. Li [10] cited by Van Donk [11] states that competition can breed a demand for MTS, just as other economic phenomenon such as economies of scale, uncertainty and seasonality. Competitive pressure have shortened the life cycles for many products and increased the penalty of holding obsolete finished goods inventories. Standard planning methods lead to high forecasting errors and-as a consequence-to high safety inventories. 
Demand information and accuracy is a critical factor for achieving end product lower inventory levels and providing better customer service [12], [13] and [14]. This issue could be essential to improve customer service and warehousing costs in make to stock production systems.

\subsection{ABC/XYZ Analysis}

The Pareto principle (also known as the 80-20 rule, the law of the vital few, and the principles of factor sparcity) serves as a baseline for ABC-analysis and XYZ-analysis. The ABC/XYZ Analysis is used to generate the supply and inventory control and production strategy. Rushton et al [15] state that it is useful in logistics and procurement for the purpose of optimizing stock of goods. The analysis consists of a procedure of stock management with which on the basis empirical experiences, results are usually assigned to a classification by the determination by variation and/or fluctuation coefficients of goods concerning its turnover regularity (consumption and its predictability). Items with high sales are called A-articles, while $\mathrm{C}$-articles have low consumption. Articles which are sold very regularly and in some extent constant are called X-Articles, while Z-class runs very irregularly or even stochastically (see Figure 2).

ABC/XYZ Analysis would be automatically generated by means of a tool, and finished goods would be checked and then assigned to the proper supply classes. After that, for each supply classes the most effective replenishment strategy is settled to increase service and optimize stock.

\subsection{Demand Forecasting}

Demand forecasting qualitative and quantitative methods can aid in establishing the right replenishment strategy [16]. To sort out the adequate qualitative and/or quantitative method some authors propose selection decision trees [17].

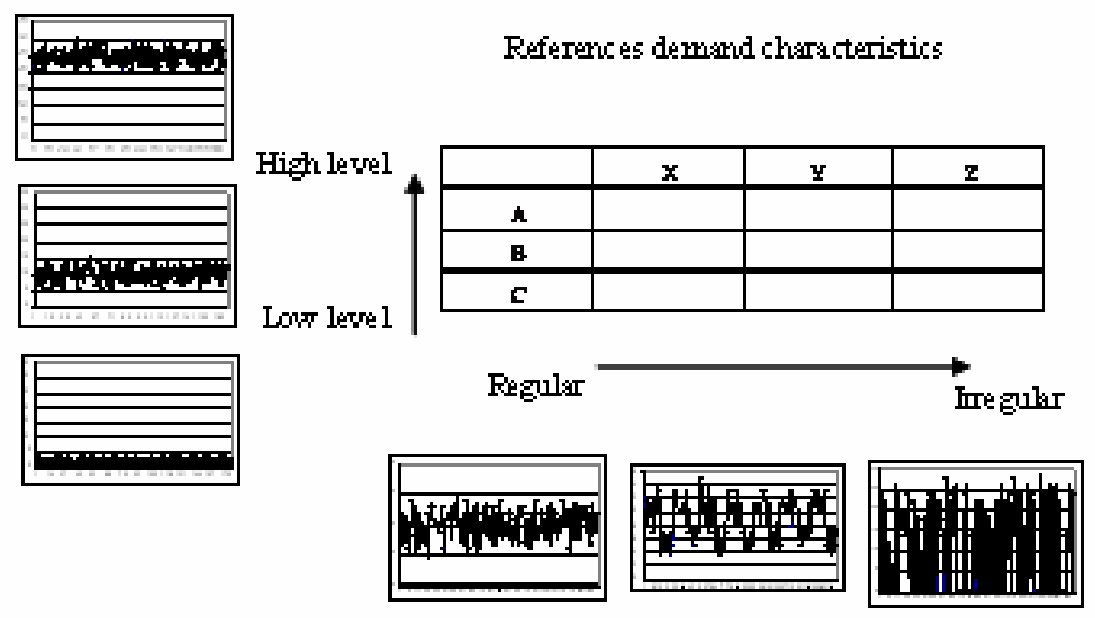

Fig. 2. ABC/XYZ References demand characteristics chart 
In recent decades, numerous time series forecasting models have been proposed. De Gooijer and Hyndman [18]performed a review of the last 25 years. Time series forecasting software tools usually offer a variety of techniques, some of which provide the user the possibility to automatically define parameters or, even, to select the best forecasting method.

Model predictive inventory control systems have been previously applied to supply chain problems with promising results [19], however most systems that have been proposed so far possess no information on future demand. The incorporation of a forecasting methodology for individual item forecasts could promote the efficiency of control actions by providing insight in the future. This efficiency would be based on more accurate predictions to forecast demand extrapolating historical data aided on time series forecasting.

Demand is one of the greatest sources of uncertainty and, selecting the best time series forecasting model for each time series to be dealt with is still a complex problem [20]. This could be the reason why only $2 \%$ of 120 interviewed companies a forecasting system based on forecasting software [21].

According to Shah [22] the sense in which accuracy is defined may vary. Examples include the mean square error (MSE) and the mean absolute deviation (MAD) as two possible ways of stating the forecast accuracy. The main advantage of those measures is that could be used for intermittent demand, while others have problems.

Commercial software packages often report the mean absolute percentage error (MAPE) distinguishing between in-sample and out-of-sample evaluations. But there are special cases, e.g. intermittent demand, in which these error measures are not appropriate [23].

In-sample and out-of-sample errors have been used for time series forecasting model selection. In-sample tests are used when the real values are known and out-ofsample test when the real values are unknown. However, some authors use out-ofsample simulation [24]. Makridakis [25] used this procedure with a rolling temporal horizon as a selection method for estimation of parameters.

Makridakis et al [26] applied out-of-sample simulation on time series, and demonstrated that forecast accuracy improves when forecasting parameters were defined out-of-sample errors rather than in-sample ones.

An alternative model selection method is the so-called cross validation method [27]. Data is partitioned into subsets in such a way that the analysis is initially performed on a single subset, while the other subset(s) is/are retained for subsequent use in confirming and validating the initial analysis. The mean squared prediction errors in the subsets left out defines the cross validation error.

Forecast accuracy can be improved by the consideration of relevant information beyond historical data. Collaborative forecasting is based on the fact that each interrelated company (customers and suppliers, or nodes in an enterprise network) has relevant information available to forecast what the rest do not have. It is a question of managing all sources of relevant information and of eliminating "analysis islands". Poler et al. [28] proposed a structured model for the collaboration among firms of a network in the demand forecast and production planning settings and analysed the impact of collaboration mechanisms on forecast accuracy. 


\section{The Inventory Replenishment Expert System}

The Inventory Replenishment Expert System (IRES) is composed by four main modules (see Figure 3).

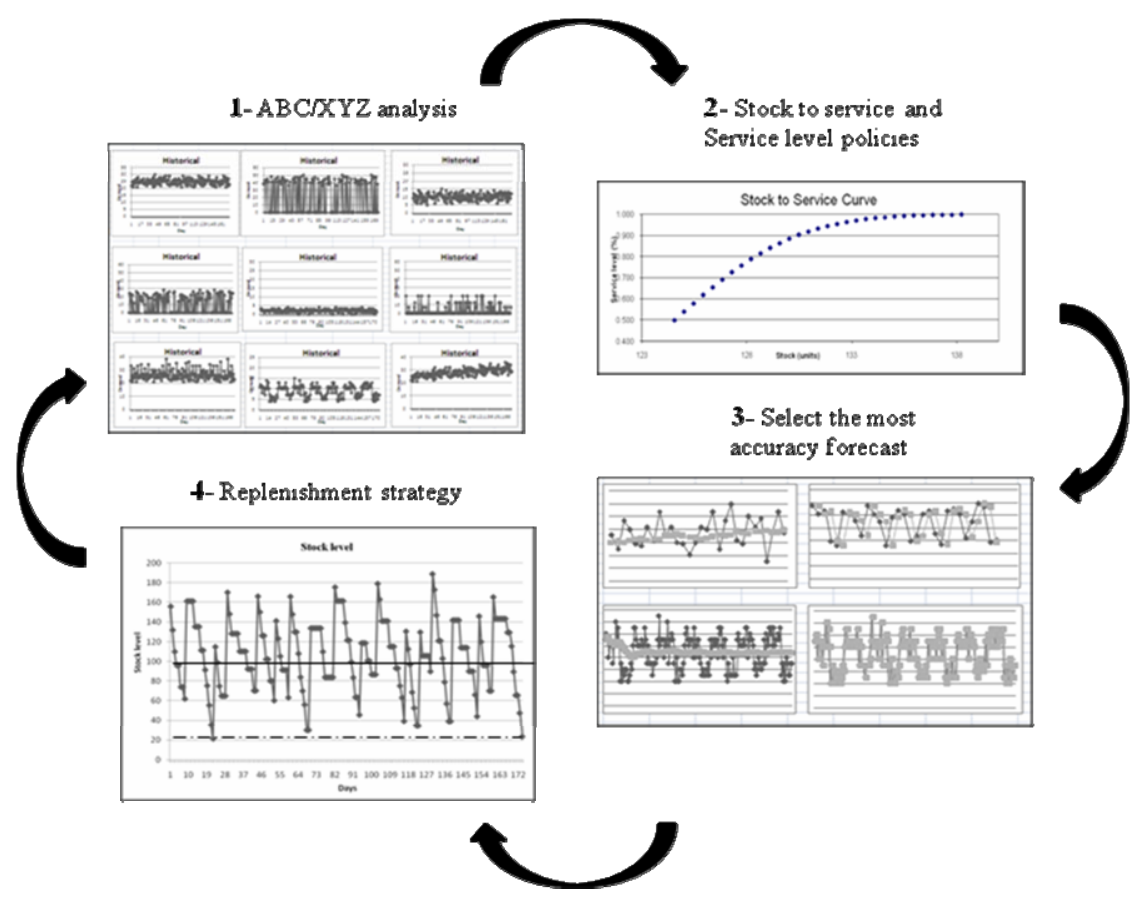

Fig. 3. The Inventory Replenishment Expert System (IRES)

The first module performs $\mathrm{ABC} / \mathrm{XYZ}$ analysis for each reference type. All types of references, according to this analysis, are sorted out taking into account the demand behavior for a given past horizon.

The second module simulates possible service policies aided with Stock to Service curves, which relate service and stock level, and allow comparing service level policies with performance rates such as stock turnover and stock out.

The third module selects the most appropriate time series forecasting model. Depending on the pattern of time series, different forecasting models might be used. The selection of the most accurate forecasting method among a set of forecasting methods is made. The selection criteria pursue to minimize a concrete forecast error measure (MSE, MAD, MAPE, etc.), which depends on each particular case, using an out-ofsample simulation with rolling time horizon was carried out.

The fourth module proposes the best replenishment strategy taking into account the demand forecasts obtained by the selected method. 


\section{Empirical Study}

The OEM, which led the supply chain improvement, was a Washing Machine Business Unit devoted to design, production and distribution of washing machines on the European market.

In order to ease the comprehension of the case study, the main characteristics of the external supply chain (distributors or customers and suppliers network) and the internal supply chain (finished product warehouse and manufacturing plant) are presented (see Figure 4).

The Spanish Household Appliances Sector is a saturated market, with an increasing number of multinational competitors. Besides, there has been a process of concentration

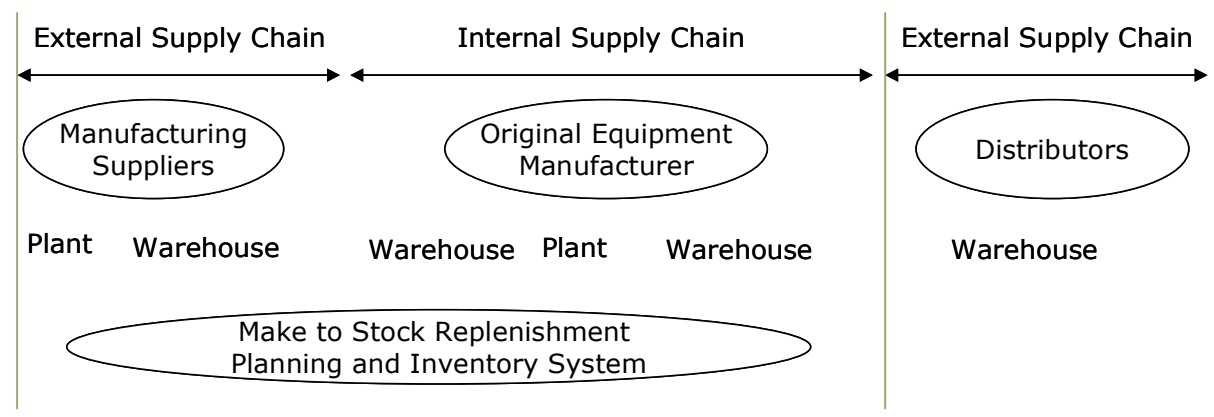

Fig. 4. Internal and external supply chain considered in the case study

Table 1. Recommended Forecasting methods and Replenishment strategies depending on make to stock references $\mathrm{ABC} / \mathrm{XYZ}$ classification

\begin{tabular}{|c|c|c|c|c|}
\hline & & X: Regular & $\begin{array}{c}\text { Y: With Trend (T) or } \\
\text { Seasonality (S) }\end{array}$ & Z: Irregular \\
\hline \multirow{2}{*}{ A: High } & $\begin{array}{l}\text { Replenishment } \\
\text { Strategy: }\end{array}$ & $\begin{array}{c}\text { Variable lot size } \\
\text { based on Forecasts }\end{array}$ & $\begin{array}{c}\text { Variable lot size based on } \\
\text { Forecasts }\end{array}$ & $\begin{array}{l}\text { Safety stock equal } \\
\text { pick consume }\end{array}$ \\
\hline & $\begin{array}{l}\text { Forecasting } \\
\text { method: }\end{array}$ & Moving Average & $\begin{array}{c}\text { (T) Exponential } \\
\text { Smoothing with trend }\end{array}$ & Moving Average \\
\hline \multirow{2}{*}{ B: Medium } & $\begin{array}{l}\text { Replenishment } \\
\text { Strategy: }\end{array}$ & $\begin{array}{c}\text { Variable lot size } \\
\text { based on Forecasts }\end{array}$ & $\begin{array}{c}\text { Variable lot size based on } \\
\text { Forecasts }\end{array}$ & $\begin{array}{l}\text { Safety stock equal } \\
\text { pick consume }\end{array}$ \\
\hline & $\begin{array}{l}\text { Forecasting } \\
\text { method: }\end{array}$ & Moving Average & $\begin{array}{l}\text { (S) Exponential } \\
\text { Smoothing with } \\
\text { Seasonality }\end{array}$ & $\begin{array}{l}\text { Exponential } \\
\text { Smoothing }\end{array}$ \\
\hline \multirow{2}{*}{ C: Low } & $\begin{array}{l}\text { Replenishment } \\
\text { Strategy: }\end{array}$ & $\begin{array}{c}\text { Variable lot size } \\
\text { based on Forecasts }\end{array}$ & $\begin{array}{c}\text { Variable lot size based on } \\
\text { Forecasts }\end{array}$ & $\begin{array}{l}\text { Safety stock equal } \\
\text { pick consume }\end{array}$ \\
\hline & $\begin{array}{l}\text { Forecasting } \\
\text { method: }\end{array}$ & $\begin{array}{l}\text { Exponential } \\
\text { Smoothing }\end{array}$ & $\begin{array}{l}(\mathrm{T})+(\mathrm{S}) \text { Exponential } \\
\text { Smoothing with Trend } \\
\text { and Seasonality }\end{array}$ & $\begin{array}{l}\text { Exponential } \\
\text { Smoothing }\end{array}$ \\
\hline
\end{tabular}


of Retailers and Wholesalers, which has caused loss of margins to the OEM and the stock ownership has passed to the OEM. In this context, the Washing machine Business Unit tried to gain a sustainable competitive advantage.

The goal of the research was to reduce the total cost of the supply chain and increase the customer service, through the implementation of an expert system for inventory management.

The implementation of the new production system was monitored with key performance indicators related to cost (stock) and customer service (order fulfillment). The results obtained are shown at Table 1.

The recalculation of safety stocks considering pick consume, and the assumption of a variable lot size replenishment strategy based on forecasts, was effective in reducing up to an $88 \%$ the number of stock-out.

\section{Conclusions}

This paper present a new Inventory Replenishment Expert System (IRES) based on the combination of ABC/XYZ analysis, Stock to Service curves, Time Series Forecasting and Replenishment Strategies.

The multidisciplinary team involved in the reengineering project has found that IRES is useful for minimizing inventory level and increasing service quality.

Future research could be done in the following areas: a) increasing the forecasting techniques of the expert system; b) analyzing the impact of different forecasting methods selection criteria; c) improving the forecasting model selection module by integrating qualitative methods such as judgmental and statistical methods; d) testing IRES in supply chains of different sectors.

\section{References}

1. Fildes, R., Nikolopoulos, K., Crone, S.F., Syntetos, A.A.: Forecasting and operational research: a review. Journal of the Operational Research Society 59(9), 1150-1172 (2008)

2. Voss, C., Tsikriktsis, N., Frohlich, M.: Case research in operations management. Int. J. Oper. Prod. Manage. 22(2), 195-219 (2002)

3. Westbrook, R.: Action Research: a new paradigm for research in production and operations management. International Journal of Operations and Production Management 15(12), 6-20 (1995)

4. Lummus, R., Vovurka, R.: Defining supply chain management: a historical perspective and practical guidelines. Industrial Management and Data Systems 99(1), 11-17 (1999)

5. Blackstone, J., Cox, F.: APICS Dictionary, 11th edn., CFPIM, CIRM, Alexandria (2004)

6. Vollmann, T.E., Berry, W.L., Whybark, D.C.: Manufacturing Planning and Control Systems, 4th edn. McGraw-Hill, Irwin (1997)

7. Rudberg, M., Wikner, J.: Mass customization in terms of the customer order decoupling point. Production Planning \& Control 15(4), 445-458 (2004)

8. Hoekstra, S., Romme, J.: Integrated Logistics Structures: Developing Customer Oriented Goods Flow. McGraw-Hill, London (1992)

9. Olhager, J.: Strategic positioning of the order penetration point. International Journal of Production Economics 85(3), 319-329 (2003) 
10. Li, L.: The role of inventory in delivery-time competition. Management Science 38(2), 182-197 (1992)

11. Van Donk, D.P.: Make to stock or make to order: The decoupling point in the food processing industries. International Journal of Production Economics 69(3), 297-306 (2001)

12. Buffa, E.S., Miller, J.G.: Production Inventory Systems: Planning and Control, 3rd edn., Homewood, IL, Irwin (1979)

13. Hax, A.C., Candea, D.: Production and Inventory Management. Prentice Hall, Englewood Cliffs (1984)

14. Silver, E.A., Pyke, D.F., Peterson, R.: Inventory Management and Production Planning and Scheduling. John Wiley and Sons, Inc., New York (1998)

15. Rushton, A., Croucher, P., Baker, P.: The handbook of logistics and distribution management. Kogan Page Publishers (2006)

16. Makridakis, S., Wheelright, S.C., Hyndman, R.J.: Forecasting: methods and applications. Wiley, Chichester (1998)

17. Armstrong, J.S., Green, K.C.: Demand Forecasting: Evidence-based Methods. In: Strategic Marketing Management: A Business Process Approach edited by Luiz Moutinho and Geoff Southern, September 14 (2005)

18. De Gooijer, J.G., Hyndman, R.J.: 25 Years of IIF Time Series Forecasting: A Selective Review. Tinbergen Institute Discussion Paper (2005)

19. Doganis, P., Aggelogiannaki, E., Sarimveis, H.: A combined model predictive control and time series forecasting framework for production-inventory systems. International Journal of Production Research 46(24), 6841-6853 (2008)

20. Poler, R., Mula, J., Peidro, D.: Parameterisation of demand forecasting models through out-of-sample errors on a rolling horizon. Dirección y Organización 37, 76-82 (2009)

21. Errasti, A.: Proyecto: Sistemas de previsión de la demanda y su aplicación a la gestión de almacenes, Cluster de Transporte y Logística de Euskadi (2009)

22. Shah, C.: Model Selection in Univariate Time Series Forecasting Using Discriminant Analysis. International Journal of Forecasting 13(4), 489-500 (1997)

23. Syntetos, A.A., Boylan, J.E.: The accuracy of intermittent demand estimates. International Journal of Forecasting 21, 303-314 (2005)

24. Coccari, R.L., Galucci, C.: Average two best forecasts can reduce forecasting risk. Journal Business Forecasting (Fall 1984)

25. Makridakis, S.: Sliding simulation: a new approach to time series forecasting. Management Science 36, 505-512 (1990)

26. Makridakis, S., Andersen, A., Carbone, R., Fildes, R., Hibon, M., Lewandowski, R., Newton, J., Parzen, E., Winkler, R.: The accuracy of extrapolation (time series) methods: results of a forecasting competition. Journal of Forecasting 1, 111-153 (1982)

27. Stone, M.: Cross validation choice and assessment of statistical predictions. Journal of the Royal Statistical Society B36, 111-147 (1974)

28. Poler, R., Hernandez, J.E., Mula, J., Lario, F.C.: Collaborative forecasting in networked manufacturing enterprises. Journal of Manufacturing Technology Management 19(4), 514$528(2008)$ 